\title{
Limitations on seismic effects of technological explosions in the combined development of the Sarbai deposit
}

\author{
Vyacheslav Kutuev ${ }^{1 *}$, and Sergey Zharikov ${ }^{1}$ \\ ${ }^{1}$ Institute of mining of the Ural branch of the Russian Academy of Sciences, 620075, 58, Mamina- \\ Sibiryaka st., Ekaterinburg, Russia
}

\begin{abstract}
The issue of joint production of drilling-and-blasting operations (DBO) is acute in the combined field workings with the condition of underground mining in the edge massif of the pit walls. Normally, the underground mine construction begins with the quarry depth approaching the end marks. In this situation, even if there is any volume for wall cutback, it is very insignificant and blasting works come closely to the limit circuit of the quarry, behind which the protected massif is located and underground workings is supposed to be carried out in the future. The main task in carrying out DBO under such conditions is to maintain the stability of this massif. Timely explosion shielding and the creation of contour fracture surfaces by applying controlled blasting reduce the negative explosion impact on the edge, yet do not always prevent the stress waves spread across the massif caused by seismic effect. Therefore, limiting the explosion seismic action in the border zone is as important for the massif stability as the professional pre-splitting.
\end{abstract}

\section{Introduction}

The following conditions must be met when mining operations are carried out in the quarry and underground mine at the same time and in the same vertical plane: protective pillar leaving for providing stability of massif and pit edges; application of mining methods that exclude the shift (destruction) of the protective pillar massif; limiting the mass blastings power and their seismic effects on the pillars, ceilings and edge benches.

As of 2012, the Sarbai iron ore deposit was worked out by a quarry, which was approaching its limit marks at the time. At the same time, more than 900 million tons of ore remained in sub-quarry reserves (in the cutoff part). To maintain the production capacity of the association, the construction of the Sarbai underground mine with a capacity of 10 million tons of crude ore per annum was planned. During the transition phase of the mine operation, combined mining of the field was planned. During this period, one of the most difficult issues was the production of blasting works - both in the quarry and in the underground mine, which should ensure not only the economic efficiency of ore breakingout, but also the safety of open and underground mining operations in the first place $[1,2]$.

\footnotetext{
*Corresponding author: slavik1988@mail.ru
} 
The work was carried out within the framework of the technological regulations for the construction project of the Sarbai underground mine on the order of JSC "Giproruda".

\section{Materials and Methods}

Blasting in the quarry must be carried out in such a way that the seismic oscillations rate of rocks in the underground working area does not exceed the maximum tolerable values for stability. To determine the permissible value of seismic oscillations rate, the allowable stresses value in the massif must be set. The allowed stress value is according to the condition of working's seismic stability [3]:

$$
\left[\sigma_{\mathrm{ss}}\right]+\left[\sigma_{\mathrm{dyn}}\right] \leq \sigma_{\mathrm{per}}
$$

where $\left[\sigma_{\mathrm{ss}}\right]-$ static stress in the massif surrounding the working, $\mathrm{MPa} ;\left[\sigma_{\mathrm{dyn}}\right]-$ dynamic stress in the massif (near development), MPa; $\sigma_{\text {per }}$ the permissible stress value, MPa.

The tensile strength limits for a sample and massif of rocks differ significantly ( 5 to 10 times or more). It is possible to estimate the value of the massif static strength limit only experimentally, which is impossible at the initial stages of design. In some cases, an approximate calculation is possible with taking into account the average structural weakening factor and on the basis of the certificate of rock strength. In rough approximation, a static tensile strength limit $\left(\sigma_{t}\right)$ increased by $10-30 \%$ [4] can be taken for the permissible stress value $\left(\sigma_{\text {per }}\right)$.

According to [5] the permissible massif offset velocity can be determined by the expression:

$$
v_{\mathrm{p}}=\frac{\sigma_{\mathrm{per}}}{\gamma C} 2604.1, \mathrm{~m} / \mathrm{s} \text {, }
$$

where $\sigma_{\text {per }}$ - permissible stress value, MPa; $\gamma-$ density of rocks, $\mathrm{t} / \mathrm{m}^{3}$; $C$ - speed of sound in rock, $\mathrm{m} / \mathrm{s}$.

The seismic oscillations velocity depending on the explosive mass per delay and the distance from the blast to the protected site can be determined according to [5]:

$$
v=K(\sqrt[3]{Q} / R)^{m}, \mathrm{~cm} / \mathrm{s}
$$

where $Q-$ mass of simultaneously exploding charges (explosive mass per delay), $\mathrm{kg} ; R$ — distance to site, $\mathrm{m} ; K$ - coefficient dependent on the explosion conditions. The $K$ value varies depending on the rocks at the explosion site and on the rocks surrounding the working. In the explosion of firm rocks and roaches surrounding the working $K=200$. In the explosion of roaches and semi-firm rocks surrounding the working $K=400$. In the explosion of semi-firm rocks and semi-firm rocks surrounding the working $K=600$; $m$ is the indicator of seismic waves attenuation. For distances up to $1500 \mathrm{~m}$, seismic wave attenuation index can be taken as equal to 1.5 .

Then the dependency (3) can be represented as:

$$
v=K \sqrt{\frac{Q}{R^{3}}}, \mathrm{~cm} / \mathrm{s} .
$$


By establishing the permissible seismic oscillations rate for a protected rocks area, it is possible to determine the distances at which blasting influence will not result in stability loss of the mountain massif near underground workings.

To determine the permissible distances from the pt outline to the underground workings, by transforming the formula (4) it is possible to express $R$, where $v_{\mathrm{p}}$ is calculated by the formula (2) and get the following expression

$$
R=\sqrt[3]{\frac{Q K^{2}}{v_{\mathrm{p}}^{2}}}, m
$$

During the major blast design at a certain quarry area, the explosive mass per delay shall be calculated taking into account the massif properties and the characteristics of the protected workings. The oscillation rate should be calculated according to the formulas (2) and (3), the $K$ coefficient and the seismic oscillations attenuation rate $m$ are determined by instrumental measurements. In the absence of the latter, the averaged dependency may be used,

$$
v=225(\sqrt[3]{Q} / R)^{1,6}, \mathrm{~cm} / \mathrm{s}
$$

which is obtained by generalization of studies results of seismic waves parameters in rock massifs by hardness $f$ from 8 to 16 on Protodiakonov scale [4].

The preservation of the passed workings is ensured if the actual shift rate $(v)$ does not exceed the permissible value $\left(v_{\mathrm{p}}\right)$ taking into account the lining type. The lining itself significantly increases the seismic resistance of the workings and can be reflected by the $K_{s r}$ coefficient. The allowed oscillation rate for workings of different purposes is presented in table 1 .

Then:

$$
v_{\mathrm{p}}=v / K_{\mathrm{sr}}, \mathrm{cm} / \mathrm{s}
$$

The values of $K_{\text {sr }}$ for different types of lining are within the following limits:

$\begin{array}{lll}\text { Without lining } & - & 1.0 ; \\ \text { Shotcreting } & - & 1.2-1.6 ; \\ \text { Anchor or roof bolting- } & 1.6-2.0 ; \\ \text { Concrete } & - & 2.2 ; \\ \text { Metal arched } & - & 2.5-3.0 .\end{array}$

Table 1. Permissible oscillation rate for workings of different purposes [6].

\begin{tabular}{|c|c|c|}
\hline Type of working & \multicolumn{2}{|c|}{ Permissible oscillation rate, cm/s } \\
\cline { 2 - 3 } & $\begin{array}{c}\text { Multiple } \\
\text { explosions }\end{array}$ & 12 \\
\hline $\begin{array}{c}\text { Particularly critical workings (lifetime of more than 10 years): } \\
\text { railway tunnels, mine shafts, main adits. }\end{array}$ & 6 & 24 \\
\hline $\begin{array}{c}\text { Critical workings (service life up to 10 years): pit bottoms, } \\
\text { main crosscuts, main entries }\end{array}$ & 12 & 48 \\
\hline $\begin{array}{c}\text { Workings with limited service life (up to 3 years): haulage cuts } \\
\text { and entries }\end{array}$ & 24 & 96 \\
\hline $\begin{array}{c}\text { Workings with a service life of up to 1 year: delivery and } \\
\text { drilling cuts and entries, upward and draw holes }\end{array}$ & 48 & 96 \\
\hline
\end{tabular}


The seismic effect of a millisecond delay blast at sufficient deceleration intervals is equivalent to the instantaneous explosion action of a single delay of a short-delay blasting. In this case, the limit is not imposed on the total mass of charges. In most cases, an explosion interval of $20-40 \mathrm{~ms}$ is sufficient.

\section{Results and Discussion}

According to the developed plans for underground workings location, the areas of the greatest impact of blasting quarry works on the stability of the mountain massif near these workings have been revealed. The smallest distances from the quarry outlines to the underground workings have been determined (Figure 1). Requirements for the drilling-andblasting operations production in the adjacent zone were established. As an example, table 2 presents the calculation results for the horizon $-185 \mathrm{~m}$.
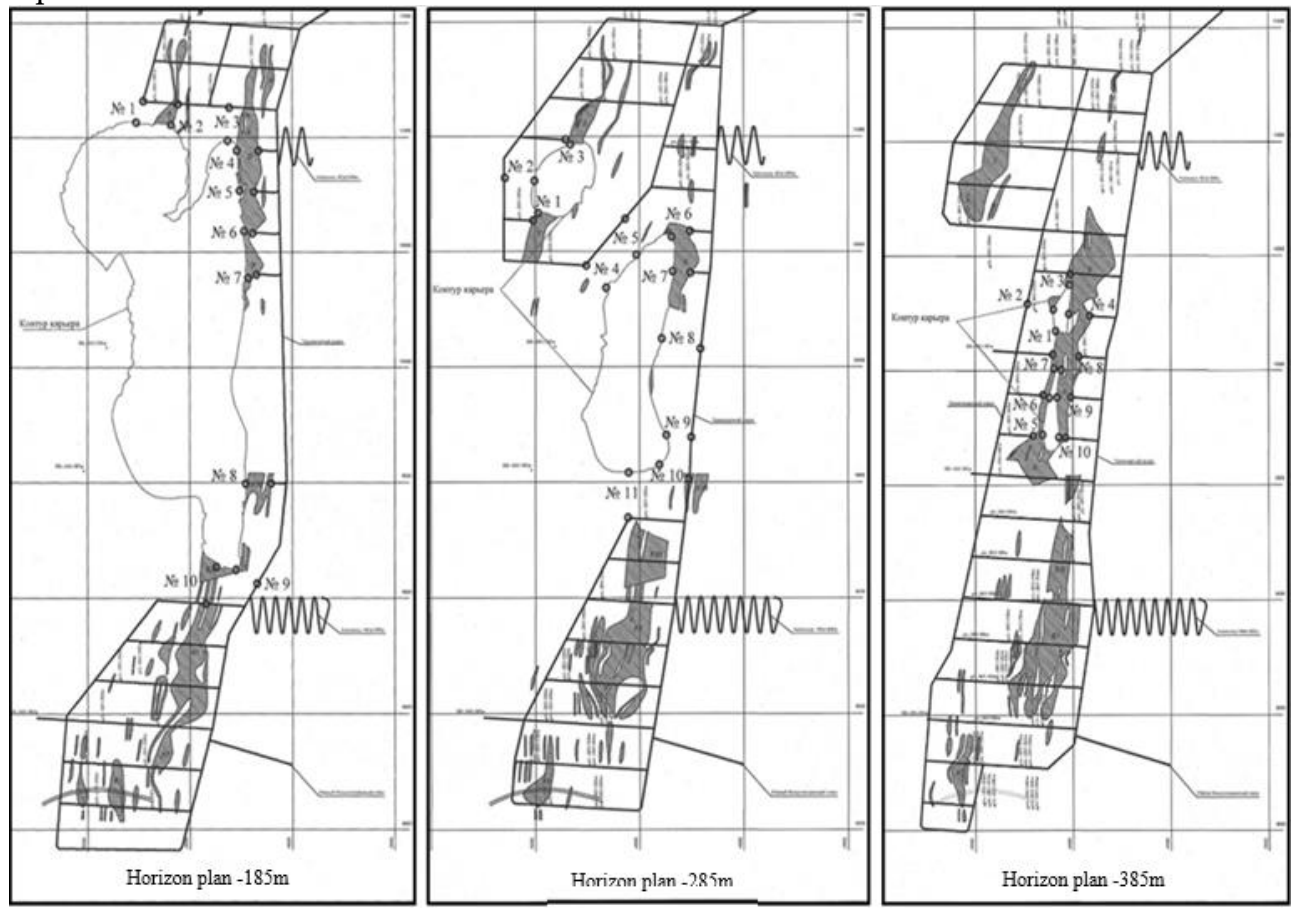

Fig. 1. The smallest distances from the quarry outlines to the underground workings.

Table 2. The smallest distances from the quarry outlines to the underground workings of the horizon $-185 \mathrm{~m}$ and recommendations on the mass explosions quarry parameters.

\begin{tabular}{|c|c|c|c|}
\hline $\begin{array}{c}\text { Number of } \\
\text { point pairs } \\
\text { in quarry } \\
\text { and } \\
\text { underground } \\
\text { workings }\end{array}$ & $\begin{array}{c}\text { Soil } \\
\text { conditions } \\
\text { coefficient, } K\end{array}$ & $\begin{array}{c}\text { Lowest } \\
\text { distance } \\
\text { between } \\
\text { pairs of } \\
\text { points, } R, \mathrm{~m}\end{array}$ & $\begin{array}{c}\text { Recommendations for carrying out DBO } \\
\text { at the specified quarry location }\end{array}$ \\
\hline 1 & 300 & 97 & \begin{tabular}{c} 
Explosive mass per delay - not more than $4000 \mathrm{~kg}$ \\
\hline 2
\end{tabular} \\
\hline 200 & 100 & $\begin{array}{c}\text { Explosive mass per delay - not more than } 3000 \mathrm{~kg} \text { or } \\
\text { not more than } 5000 \mathrm{~kg} \text { and blast shielding }\end{array}$ \\
\hline 3 & 300 & 144 & Explosive mass per delay - not more than $9000 \mathrm{~kg}$ \\
\hline 4 & 200 & 103 & Explosive mass per delay - not more than $4000 \mathrm{~kg}$ \\
\hline
\end{tabular}




\begin{tabular}{|c|c|c|}
\hline 5 & 68 & Explosive mass per delay - not more than $1000 \mathrm{~kg}$ \\
\hline 6 & 42 & \multirow{2}{*}{$\begin{array}{c}\text { Explosive mass per delay - not more than } 500 \mathrm{~kg} \text {, } \\
\text { blast shielding }\end{array}$} \\
\hline 7 & 41 & \\
\hline 8 & 123 & Explosive mass per delay - not more than $4000 \mathrm{~kg}$ \\
\hline 9 & 118 & Explosive mass per delay - not more than $3000 \mathrm{~kg}$ \\
\hline 10 & 160 & Explosive mass per delay - not more than $8000 \mathrm{~kg}$ \\
\hline
\end{tabular}

For horizons -285 and $-385 \mathrm{~m}$, similar calculations were made according to the method of Institute of Mining Engineering, Ural branch of the RAS [6] depending on the soil conditions coefficient $(\mathrm{K})$ and the distances between the points chosen on the plan $(\mathrm{R})$; the appropriate recommendations for conducting careful blasting in the conditions of the Sarbai quarry were given.

\section{Conclusion}

Based on the seismic restriction, other parameters of mass explosions in the quarry are determined. The calculated permissible value of charges is indicative. During the design of specific mass explosions at a particular quarry area, this value must be calculated taking into account the massif properties and the characteristics of the protected workings.

The magnitude of underground technological explosions during the quarry operation is limited to the DBO parameters during raise work and practically should not exceed a few kilograms per each delay. As a result, these explosions do not have a seismic effect on the slope protective structures.

Currently, the means of blasting can provide independent operation of each explosive charge in the bore [7-9], that is, using this approach it is possible to optimize the drilling operations parameters and to achieve a significant reduction in the effect of the explosion seismic impact on the protected massif and quarry objects in the joint operation of blasting works on the surface and underground workings within the combined development of the field.

\section{Acknowledgements}

The research was carried out within the framework of the State order, the theme № 0405 2019-0005 (2019 - 2021), as well as with additional attraction of contractual funds.

\section{References}

1. Federal regulations and rules on industrial safety. Safety rules for blasting (TH "UralYurIzdat", Ekaterinburg, 2018)

2. Federal regulations and rules on industrial safety. Safety rules for mining operations and processing of solid minerals (TH "UralYurIzdat", Ekaterinburg, 2018)

3. V. A. Schelkanov, P. S. Mironov, Proceedings of the Ministry of Emergency Situations of the USSR: Drilling-and-blasting operations in ore pits, 36, 91 (1972)

4. M. I. Kartuzov, N. V. Pazdnikov, Prediction of seismic safety of underground workings in explosions, (IM MFM USSR, Sverdlovsk, 1982)

5. I. F. Bondarenko, S. N. Zharikov, I. V. Zyryanov [et al.], Drilling-and-blasting operations on kimberlite quarries of Yakutia (IM UB RAS, Ekaterinburg, 2017)

6. M. I. Kartuzov, N. V. Pazdnikov, Methodology of providing seismic safe explosive technology (IM MFM USSR, Sverdlovsk, 1984) 
7. W. Yuan, S. Liu, W. Wang [et al.], Earthq. Eng. Eng. Vib., 18, 735 (2019)

8. F. Vanbrabant, A. Espinosa, Proc. 8th Int. Symp. on Rock Fragmentation by BlastingFragblast, 8, 326 (2006)

9. Y. Changping, D. Johansson, U.Nyberg [et al.], Rock Mechanics and Rock Engineering 49, 1803 (2016) 